\title{
Seponering av antiepileptika ved anfallsfrihet - når og hvordan?
}

\author{
Hos anfallsfrie epilepsipasienter kan spørsmålet om og eventuelt når det \\ er forsvarlig å avslutte behandlingen være vanskelig å besvare. Sammen \\ med pasient og pårørende bør man gjøre en grundig nytte-risiko-vurde- \\ ring, der konsekvensene av tilbakefall må veies opp mot ulempene med \\ fortsatt medisinering. Som hovedregel bør voksne pasienter ha vært \\ anfallsfrie i minst to år før man vurderer seponering. Hos barn med \\ epilepsi med kjent god prognose kan seponering vurderes tidligere.
}

Med antiepileptiske legemidler blir $60-70 \%$ av pasienter med nydiagnostisert epilepsi anfallsfrie (1). Selv om man hos mange etter hvert vil kunne avslutte legemiddelbehandlingen, er det ikke uvanlig at den fortsetter. Enkelte pasienter og deres pårørende stiller spørsmål ved berettigelsen av dette. Vurderingen av om man bør seponere antiepileptika, og eventuelt når, er en vanskelig problemstilling for både kliniker og pasient.

Hensikten med denne artikkelen er å gi en kort oversikt over hva som kan tale for og hva som kan tale imot å avslutte antiepileptisk behandling. Den er basert på aktuelle studier identifisert ved et litteratursøk med søkeordene «antiepileptic drug withdrawal/ discontinuation, adults, children», med en etterfølgende skjønnsmessig litteraturgjennomgang, i tillegg til egne erfaringer. Vi gir også noen praktiske råd om denne beslutningsprosessen.

\section{Argumenter for seponering}

Over halvparten av dem som bruker antiepileptika, rapporterer om bivirkninger (2), og mange er bekymret for langtidsbivirkninger (3). Særlig er mange foreldre opptatt av hva bruken av slike legemidler kan bety for barnas utvikling og læring $(4,5)$. Det er vist at antiepileptikabruk kan ha en negativ påvirkning på kognitive funksjoner hos både barn og voksne $(4,6)$ og at kognitive prestasjoner blir bedre etter seponering $(7,8)$.

Antiepileptiske midler kan dessuten påvirke atferd, humør og våkenhet (2). I tillegg kan de ha en negativ påvirkning på lipidprofilen samt på endokrine og kardiale funksjoner. En norsk studie viste at seponering ga en reversering av slike bivirkninger (9-11).

I barnealder finnes det mange epilepsiformer med høyst forskjellig prognose. Ved ca. $15 \%$ av disse ses nesten alltid varig remisjon, og hos barn som har en epilepsiform med god prognose, bør seponering alltid forsøkes (12). Fordi 50-60\% av alle barn med epilepsi kan oppnå anfallsfrihet uten medisiner 10-20 år etter anfallsdebuten (12), bør spørsmålet om seponering diskuteres for alle barn som er blitt anfallsfrie. Dog må man ta hensyn til faktorene i ramme 1 (7, 13-15).

Ved å stoppe legemiddelbruken kan man ikke bare forebygge kroniske bivirkninger, man unngår også interaksjoner med andre legemidler og eventuelle fosterskadelige effekter under graviditet. Mange opplever dessuten at de blir «friskmeldte» når de ikke lenger må ta legemidler hver dag. Unødig legemiddelbruk utgjør også en kostnad for samfunnet.

Tilbakefall av anfall etter seponering viser at fortsatt medisinering er nødvendig.

\section{Argumenter mot seponering}

Snaut $70 \%$ av pasientene oppnår god anfallskontroll med antiepileptika (1), og legemidlene gjør at deres liv er lite påvirket av epilepsien. Flere av de nye midlene ser ut til å ha en bedre bivirkningsprofil enn de eldre enzyminduserende stoffene $(2,3)$. Medisinene gir trygghet og beskytter mot anfallsrelaterte uhell.

Tilbakefall av anfall er ikke bare en psykisk belastning, det kan også få andre alvorlige konsekvenser (13) - for eksempel tap av førerkort, med alt det innebærer. Noen risikerer å miste jobben dersom denne krever førerkort eller dersom anfall kan sette eget og/eller andres liv og helse i fare. I tillegg kommer psykososiale problemer, inkludert stigmatisering, og i verste fall plutselig, uventet epilepsirelatert død (sudden unexpected death in epilepy, SUDEP), selv om dette heldigvis er sjelden (16-18).

A fjerne de anfallsbeskyttende medisinene innebærer at $15-41 \%$ av pasientene får anfallsresidiv $(7,13)$. Det er imidlertid viktig å huske at også av anfallsfrie pasienter som fortsetter med medisiner, vil 7-20\% få anfallsresidiv i løpet av 1-2 år $(7,13)$.

\author{
Morten I. Lossius \\ Kristin A. Alfstad \\ Kari M. Aaberg \\ Karl O. Nakken \\ karln@ous-hf.no \\ Spesialsykehuset for epilepsi (SSE)
}

Engelsk oversettelse på www.tidsskriftet.no

HOVEDBUDSKAP

Voksne pasienter med epilepsi bør ha vært anfallsfrie i minst to år før seponering av antiepileptika vurderes

Hos barn som har en epilepsiform med god prognose, kan man vurdere å seponere antiepileptika tidligere

Risiko og nytte ved seponering må drøftes nøye med pasient og pårørende

Ved anfallsresidiv etter seponeringen vil de aller fleste gjenvinne anfallskontrollen etter oppstart av samme medikamentelle behandling som før 


\section{RAMME 1}

Kliniske faktorer som gir økt risiko for tilbakefall av anfall etter seponering av antiepileptika hos barn (7, 13-15)

Tidlig anfallsdebut (< 2 år)

Anfallsdebut i ungdomsalder ( 10 år)

Symptomatisk epilepsi lanfallsgenererende substrat påvist på MR-undersøkelse)

Spesielle epilepsisyndromer, for eksempel Lennox-Gastauts syndrom eller juvenil myoklon epilepsi

Nevrologiske utfall

Flere anfallstyper

Utviklingshemning

Bruk av mer enn ett antiepileptikum

Patologisk EEG, epileptiform aktivitet eller langsom bakgrunnsaktivitet

\section{Få gode studier}

Det er få gode studier på dette feltet (19). Når det gjelder voksne, finnes det to der anfallsfrie pasienter ble randomisert til enten seponering eller fortsatt behandling.

I en prospektiv, åpen randomisert studie med 1013 pasienter som hadde vært anfallsfrie i minst to år, fant man to år etter seponering tilbakefall hos $41 \%$, mot $22 \%$ i gruppen som fortsatte med behandling (13).

Den andre studien, en norsk randomisert, dobbeltblindet studie, omfattet 160 pasienter som hadde vært anfallsfrie på monoterapi i minst to år. De ble randomisert til seponering $(\mathrm{n}=79)$ eller fortsatt behandling $(\mathrm{n}=81)$. Etter 12 måneder hadde $15 \%$ i seponerings-

RAMME 2

Kliniske faktorer som gir økt risiko for tilbakefall av anfall etter seponering av antiepileptika hos voksne $(14,15)$

Sen epilepsidebut (> 16 år)

Generaliserte epileptiforme EEG-forstyrrelser siste år

Opplysninger om myoklonier, fokale anfall med påvirket bevissthet og/eller toniskkloniske anfall

Anfall etter start av behandlingen

Bruk av mer enn ett antiepileptikum

Nevrologiske utfall gruppen og $7 \%$ i gruppen med fortsatt behandling fått tilbakefall. I en åpen oppfølgingsstudie valgte $89 \%$ av pasientene som var trukket ut til fortsatt behandling, å slutte med medikamentet. Etter 41 måneder hadde $27 \%$ av dem som hadde avsluttet behandlingen fått tilbakefall (7).

Den relativt lave tilbakefallsprosenten i denne studien sammenlignet med tilbakefallsprosenten i den første, kan forklares ved at inklusjonskriteriene var strengere $\mathrm{i}$ den siste studien. I begge studiene ble det funnet dobbelt så høy risiko for anfall hos dem som seponerte sammenlignet med dem som fortsatte med antiepiletika.

En metaanalyse basert på 25 observasjonsstudier rapporterte om anfallsresidiv hos $25 \%$ etter ett år og hos $29 \%$ to år etter seponering (20). I en amerikansk retningslinje basert på 17 observasjonsstudier konkluderte man med en tilsvarende rate etter seponering på $31,2 \%$ for barn og $39,4 \%$ for voksne (21).

Når det gjelder barn, finnes det en oversikt basert på 12 observasjonsstudier med over 2500 barn. Den viste anfallsresidiv ett år etter seponering hos 4-33\% og hos 9-39\% etter to år. Variasjonen i residivrate skyldes sannsynligvis forskjeller i epilepsiform, epilepsietiologi og tilleggsvansker hos barna som inngikk i studiene. Risikoen for anfallsresidiv var høyest de første 12 månedene (22).

I en Cochrane-oversikt basert på fem studier med til sammen over 900 barn konkluderte man med $34 \%$ økt risiko for anfallsresidiv dersom barna hadde vært anfallsfrie i under to år, sammenlignet med dem som seponerte etter mer enn to års anfallsfrihet. Risikoen for tilbakefall ved tidlig seponering var ytterligere økt dersom barna hadde fokale anfall, psykisk utviklingshemning og/eller patologisk EEG-resultat (23).

Ved farmakoresistent epilepsi, det vil si hos pasienter som ikke oppnår anfallskontroll etter å ha forsøkt to relevante antiepileptika, bør andre behandlingsformer vurderes. Av dem som etter en grundig utredning blir funnet egnet for resektiv epilepsikirurgi, blir rundt $60 \%$ kvitt anfallene etter temporallappsreseksjoner, mens $30-40 \%$ blir anfallsfrie etter ekstratemporal kirurgi (24). Flertallet av dem som er anfallsfrie to år etter operasjonen, fortsetter å være det $\mathrm{i}$ årene fremover. Noen får imidlertid anfallsresidiv etter mange års anfallsfrihet, selv ved fortsatt antiepileptikabruk $(24,25)$.

Det er ikke utført noen randomiserte, kontrollerte studier med pasienter som seponerer antiepileptika etter epilepsikirurgi. Ved flere av observasjonsstudiene på dette feltet er det seleksjonsskjevhet - det er gjerne de med antatt best utsikter til fortsatt anfallsfrihet som blir valgt ut for seponering (25).

\section{Prediktorer for anfallsresidiv}

For noen pasienter er det større risiko for tilbakefall etter seponering enn andre. Det har imidlertid vært vanskelig å finne konsistente prediktorer for anfallsresidiv (26). Ramme 1-3 viser de antatt viktigste risikofaktorene hos henholdsvis voksne og barn og hos dem som har gjennomgått epilepsikirurgi. Det er viktig å understreke at ingen av disse faktorene alene utgjør en kontraindikasjon mot seponering, men når det foreligger en kombinasjon av flere slike faktorer, vil risikoen $ø$ øe (26). Nevrologiske utfall hos pasienter før seponering er vist å være en uavhengig negativ prediktor $(7,13)$. Etter vår erfaring bør man også være forsiktig med å seponere legemidlene hos pasienter med en strukturell hjernelesjon, patologisk EEG og fokale anfall med påvirket bevissthet.

Ved noen epilepsiformer hos barn, for eksempel benigne neonatale og infantile epilepsier, rolandisk epilepsi og Panayiotopoulos' syndrom, oppnår nesten alle remisjon. Dersom man har valgt å starte medikamentell behandling av disse pasientene, bør det alltid legges en plan for varigheten. Når man skal vurdere seponering, er det viktig å ta hensyn til faktorer som øker risikoen og til faktorer som reduserer risikoen for tilbakefall - alder ved epilepsidebut, epilepsiårsak, epilepsiform, EEG-funn og nevrologiske og utviklingsmessige tilleggsvansker, jf. ramme 1-4 $(14,22,27)$.

Etter kirurgi vil epileptiform aktivitet i EEG og restforandringer på MR øke risikoen for anfallsresidiv ved seponering, jf. ramme 3 .

\section{Anfallskontroll etter ny behandlingsoppstart?}

De aller fleste vil bli anfallsfrie når de får tilbake legemidlene som opprinnelig ga dem anfallskontroll. Selv om resultatene fra studier på dette feltet er sprikende, er det holdepunkter for at det er over $80 \%$ sjanse for at man får tilbake anfallskontroll om man gjeninnsetter samme legemiddel i samme dose som tidligere $(28,29)$.

\section{Diskusjon og noen praktiske råd}

Det finnes ingen sikker kunnskap om hva som er det optimale tidspunkt å avslutte behandlingen på hos anfallsfrie pasienter (30). Som generell regel mener vi at både barn og voksne bør ha vært anfallsfrie i minimum to år. Ved barneepilepsier som erfaringsmessig ofte går i remisjon, kan man vurdere å seponere tidligere. Også hos dem som blir anfallsfrie etter epilepsikirurgi, vil vi anbefale å vente med seponering av medikasjonen til det er gått to år etter inngrepet. I noen tilfeller kan det være aktuelt med en forenkling av behandlingen noe tidligere - fra polyterapi til monoterapi - særlig hvis pasienten har sjenerende bivirkninger. 
RAMME 3

Kliniske faktorer som gir økt risiko for tilbakefall av anfall etter seponering av antiepileptika hos epilepsiopererte $(14,15)$

Eldre enn 30 år ved kirurgi

Lang varighet av epilepsien

Tidlig seponering ( $<2$ år etter inngrepet)

Persisterende fokale anfall med bevart bevissthet

Tilbakefall ved tidligere seponeringsfors $ø k$

Postoperative epileptiforme EEG-forstyrrelser

Holdepunkter for cerebral gliose eller restforandringer på postoperativ MR

Fokal kortikal dysplasi som epilepsietiologi

Nevrologiske utfall

Hos barn som fremdeles har omsorgspersoner tett rundt seg og hos dem som ennå ikke er i jobb eller har førerkort, må skaderisikoen ved eventuelle anfall veies mot risikoen for påvirkning av barnas utvikling og læring ved fortsatt medisinering. Dette, og det at sjansen for endelig remisjon er noe høyere hos barn enn hos voksne, er noe av grunnen til at terskelen for å forsøke å seponere behandlingen er lavere hos barn enn hos voksne.

Dersom det kommer tilbakefall etter seponering, er ikke dette ensbetydende med livslang behandling. Det kan være gode grunner til å gjøre et nytt forsøk på et senere tidspunkt, selv om terskelen for seponeringsforsøk nok er høyere i slike tilfeller.

Risikoen for tilbakefall er ikke signifikant forskjellig om man nedtrapper legemidlene

\section{RAMME 4}

Faktorer som taler for en vellykket seponering av antiepileptika (14)

Anfallsfrihet i over to år

Rask anfallsfrihet etter oppstart av behandling

Normal nevrologisk status og normal psykomotorisk utvikling

Normalt EEG og normal cerebral MR

Epilepsiform med kjent god prognose

Anfallsdebut i barnealder (2-10 år) raskt (seks uker) eller langsomt (ni måneder) (30). Dersom man velger å seponere, vil vi, basert på vår kliniske erfaring, anbefale nedtrapping over minst åtte uker. Ved nedtrapping av fenobarbital eller klonazepam anbefaler vi $12-24$ uker.

Det finnes ingen sikker kunnskap om at avslutning av behandlingen påvirker langtidsprognosen hos pasienter som enten er blitt anfallsfrie med antiepileptika eller etter epilepsikirurgi. Det diskuteres om seponering $i$ den første gruppen kun avdekker epilepsiens naturlige forløp og i den andre demaskerer det sanne postoperative utfallet (14).

Beslutningen om å avslutte behandling med antiepileptika er en spesialistoppgave. Spørsmålet bør drøftes nøye med pasienten og eventuelle pårørende. Nytte og risiko må veies mot hverandre. Ettersom ingen pasienter har helt lik risikoprofil, vil beslutningen måtte fattes individuelt ut fra pasientens risikofaktorer for anfallsresidiv. Det er viktig å diskutere de mange mulige konsekvensene av et tilbakefall og lytte nøye til pasientens og eventuelt pårørendes egne preferanser. Hvis man velger å fortsette behandlingen, bør man vurdere risikoen for langtidsbivirkninger og eventuelt muligheten av å forebygge disse (3).

\section{Morten I. Lossius (f. 1962)}

er overlege, dr.med. og spesialist i nevrologi. Hans doktorarbeid bygde på studier over seponering av antiepileptika hos anfallsfrie voksne. Han er leder av forskningsgruppen ved epilepsisykehuset.

Forfatter har fylt ut ICMJE-skjemaet og oppgir følgende interessekonflikter: Han har mottatt honorar fra Eisai og UCB for foredrag og deltagelse i rådgivningsgruppen.

\section{Kristin Å. Alfstad (f. 1966)}

er overlege, ph.d. og spesialist i nevrologi. Hun jobber med utredning av pasienter for epilepsikirurgi og oppfølging etter operasjonen. Forfatter har fylt ut ICMJE-skjemaet og oppgir ingen interessekonflikter.

\section{Kari M. Aaberg (f. 1973)}

er overlege og spesialist i barnesykdommer. Som stipendiat er hun for tiden i gang med epidemiologiske studier om barn med epilepsi. Forfatter har fylt ut ICMJE-skjemaet og oppgir ingen interessekonflikter.

\section{Karl O. Nakken (f. 1945)}

er overlege, dr.med. og spesialist i nevrologi. Han har spesialkompetanse innen epileptologi og er medisinsk fagsjef ved epilepsisykehuset. Forfatter har fylt ut ICMJE-skjemaet og oppgir følgende interessekonflikter: Han har mottatt honorar fra Eisai for foredrag og for deltagelse i rådgivningsgruppen.
Litteratur

1. Kwan P. Brodie MJ. Early identification of refractory epilepsy. N Engl J Med 2000: 342: 314-9.

2. Perucca P, Gilliam FG. Adverse effects of antiepileptic drugs. Lancet Neurol 2012; 11: 792-802.

3. Svendsen T, Alfstad K $\AA$, Lossius Ml et al. Langtidsbivirkninger av antiepileptika. Tidsskr Nor Legeforen 2016; 136: 324-7.

4. Lagae L. Cognitive side effects of anti-epileptic drugs. The relevance in childhood epilepsy. Seizure 2006; 15: 235-41.

5. Cross JH. Neurodevelopmental effects of antiepileptic drugs. Epilepsy Res 2010; 88: 1-10.

6. Mula M, Trimble MR. Antiepileptic drug-induced cognitive adverse effects: potential mechanisms and contributing factors. CNS Drugs 2009; 23 ; $121-37$.

7. Lossius MI, Hessen E, Mowinckel P et al. Consequences of antiepileptic drug withdrawal: a randomized, double-blind study (Akershus Study). Epilepsia 2008; 49: 455-63.

8. Boshuisen $\mathrm{K}$, van Schooneveld MM, Uiterwaal CS et al. Intelligence quotient improves after antiepileptic drug withdrawal following pediatric epilepsy surgery. Ann Neurol 2015; 78: 104-14.

9. Lossius MI, Erikssen JE, Mowinckel P et al. Changes in autonomic cardiac control in patients with epilepsy after discontinuation of antiepileptic drugs a randomized controlled withdrawal study. Eur J Neurol 2007: 14: 1022-8.

10. Lossius MI, Taubøll E, Mowinckel $P$ et al. Reversible effects of antiepileptic drugs on reproductive endocrine function in men and women with epilepsy - a prospective randomized double-blind withdrawal study. Epilepsia 2007: 48: 1875-82.

11. Lossius MI, Nakken KO, Mowinckel P et al. Favor able change of lipid profile after carbamazepine withdrawal. Acta Neurol Scand 2016; 134: 219-23.

12. Camfield PR, Camfield CS. What happens to children with epilepsy when they become adults? Some facts and opinions. Pediatr Neurol 2014; 51: 17-23.

13. Medical Research Council Antiepileptic Drug Withdrawal Study Group. Randomised study of antiepileptic drug withdrawal in patients in remission. Lancet 1991; 337: 1175-80.

14. Braun KP, Schmidt D. Stopping antiepileptic drugs in seizure-free patients. Curr Opin Neurol 2014; 27: 219-26.

15. Shinnar S, Berg AT, Moshé SL et al. Discontinuing antiepileptic drugs in children with epilepsy: a prospective study. Ann Neurol 1994; 35: 534-45.

16. Schmidt D. AED discontinuation may be dangerous for seizure-free patients. J Neural Transm (Vienna) 2011. 118: 183-6.

17. Mansouri A, Alhadid K, Valiante TA. Sudden unexpected death in epilepsy following resective epilepsy surgery in two patients withdrawn from anticonvulsants. J Clin Neurosci 2015: 22: 1505-6.

18. Aurlien D, Olsen TR, Taubøll E et al. Plutselig, uventet epilepsirelatert død. Tidsskr Nor Legeforen 2016; 136: $131-5$

19. Rathore C, Paterson R. Stopping antiepileptic drugs in patients with epilepsy in remission: why when and how? Neurol India 2014; 62: 3-8.

20. Berg AT, Shinnar S. Relapse following discontinuation of antiepileptic drugs: a meta-analysis. Neurology 1994: 44: 601-8.

21. Practice parameter: a guideline for discontinuing antiepileptic drugs in seizure-free patients - sum mary statement. Report of the Quality Standards Subcommittee of the American Academy of Neurology. Neurology 1996: 47: 600-2.

22. Specchio LM, Beghi E. Should antiepileptic drugs be withdrawn in seizure-free patients? CNS Drugs 2004; 18: 201-12

23. Strozzi I, Nolan SJ, Sperling MR et al. Early versus late antiepileptic drug withdrawal for people with epilepsy in remission. Cochrane Database Syst Rev 2015; 2: CD001902

24. Wiebe S. Epilepsy. Outcome patterns in epilepsy surgery-the long-term view. Nat Rev Neurol 2012; 8. $123-4$ 


\section{KLINISK OVERSIKT}

25. Boshuisen K, Arzimanoglou A, Cross JH et al.

Timing of antiepileptic drug withdrawal and longterm seizure outcome after paediatric epilepsy surgery (TimeToStop): a retrospective observational study. Lancet Neurol 2012; 11: 784-91.

26. Lamberink HJ, Otte WM, Geleijns K et al. Antiepileptic drug withdrawal in medically and surgically treated patients: a meta-analysis of seizure recurrence and systematic review of its predictors. Epileptic Disord 2015; 17: 211-28.

27. Beghi E, Giussani G, Grosso S et al. Withdrawal of antiepileptic drugs: guidelines of the Italian League Against Epilepsy. Epilepsia 2013; 54 (suppl 7): 2-12.

28. Camfield P, Camfield C. The frequency of intractable seizures after stopping AEDs in seizure-free children with epilepsy. Neurology 2005; 64: 973-5

29. Schmidt D, Löscher W. Uncontrolled epilepsy following discontinuation of antiepileptic drugs in seizure-free patients: a review of current clinical experience. Acta Neurol Scand 2005; 111: 291-300.

30. Ranganathan LN, Ramaratnam S. Rapid versus slow withdrawal of antiepileptic drugs. Cochrane Database Syst Rev 2006; 2: CD005003. Review.

Mottatt 9.11. 2016, første revisjon innsendt 21.1. 2017, godkjent 13.2. 2017. Redaktør: Lars Frich. 